\title{
Total Ophthalmoplegia as a Presenting Feature in Nasopharyngeal Carcinoma - A Case Report
}

\author{
Sachin Vishwanath Daigavane ${ }^{1}$, Abhishek G.U. ${ }^{2}$ \\ 1, 2 Department of Ophthalmology, Jawaharlal Nehru Medical College, Datta Meghe Institute of Medical Sciences \\ (Deemed to Be University), Sawangi (Meghe), Wardha, Maharashtra, India.
}

\section{PRESENTATION OF CASE}

Patient is a 32-year-old healthy female, hailing from Amravathi, farmer by occupation who presented in Ophthalmology OPD with drooping of left eyelid and diminution of vision in left eye (LE) for a duration of 2 months, both of which were sudden in onset, painless and progressive in nature associated with gradual loss of vision from past 1 month. As the drooping of eyelid increased, she was unable to elevate her left eyelid. She also gives associated history of ( $\mathrm{h} / \mathrm{o}$ ) left sided nasal blockage for past 2 months with slight change in voice. Patient denied any history of trauma, redness or pain in LE, diplopia, muscular weakness or difficulty in swallowing. No h / o any hearing loss. Not a known case of diabetes mellitus, thyroid disease or hypertension.

On examination visual acuity was 6 / 6 by Snellen distant vision chart, N6 by Roman chart for near vision in right eye and PL negative in Left eye. Examination revealed normal lid in right eye and severe ptosis with poor levator palpebrae superioris function $(1 \mathrm{~mm})$ in left eye. Pupils were $2 \mathrm{~mm} /$ circular, central and reacting to light in right eye, dilated, $6 \mathrm{~mm}$ and not reacting in left eye. There was free and full ocular motility (both uniocular and binocular) in all directions of gaze in right eye, restricted in all directions of gaze in both uniocular and binocular movements in left eye (Figure 1). Slit lamp examination also revealed no abnormalities in any ocular media. IOP was $17 \mathrm{mmHg}$ and $21 \mathrm{mmHg}$ by Goldmann applanation tonometry. Ocular media were clear and fundus examination revealed pallor of disc in left eye.

ENT examination revealed a globular mass $1 \mathrm{~cm}$ in size in left posterior nasal cavity. Neck examination revealed enlarged bilateral submandibular and cervical lymph nodes measuring $>6 \mathrm{~cm}$.

Blood reports revealed Hb-12.4\%, total WBC count of 8,300 cells / $\mathrm{mm}^{3}$ and 10 $\%$ lymphocytes.

CT scan of head with paranasal sinuses reveals (Figure 2 and Figure 3). Heterogenous soft tissue mass arising from nasopharynx leading to obliteration of left nasal cavity, left eustachian tube, fossa of Rosenmuller on left side and prevertebral space.

Lesion was causing erosions and extensions as follows

- Anteriorly - Medial wall of right and left maxillary sinus.

- Inferiorly - Hard palate and upper alveolar margin on the left side and extending into left gingivo-buccal space.

- Superiorly - Destroying bilateral ethmoid sinuses, lateral wall and floor of left orbit and extending into it, sella tursica, clivus, greater and lesser wing of sphenoid bone on left side, medial and lateral pterygoid plate on left side and is extending into middle cranial fossa.

- $\quad$ Laterally - Extending into left masticator space with loss of fat plane between lesion and zygomaticus muscle.
Corresponding Author: Dr. Abhishek G.U,

Room S 14, Ragobhaji PG Boys Hostel, DMIMS, Sawangi (Meghe), Wardha,

Maharashtra, India.

E-mail:abhishekgudvg@gmail.com

DOI: $10.14260 /$ jemds/2021/51

How to Cite This Article:

Daigavane SV, Abhishek GU. Total ophthalmoplegia as a presenting feature in nasopharyngeal carcinoma - a case report. J Evolution Med Dent Sci 2021;10(04):236239, DOI: $10.14260 /$ jemds $/ 2021 / 51$

Submission 14-10-2020,

Peer Review 29-11-2020,

Acceptance 03-12-2020,

Published 25-01-2021.

Copyright (c) 2021 Sachin Vishwanath Daigavane et al. This is an open access article distributed under Creative Commons Attribution License [Attribution 4.0 International (CC BY 4.0)] 


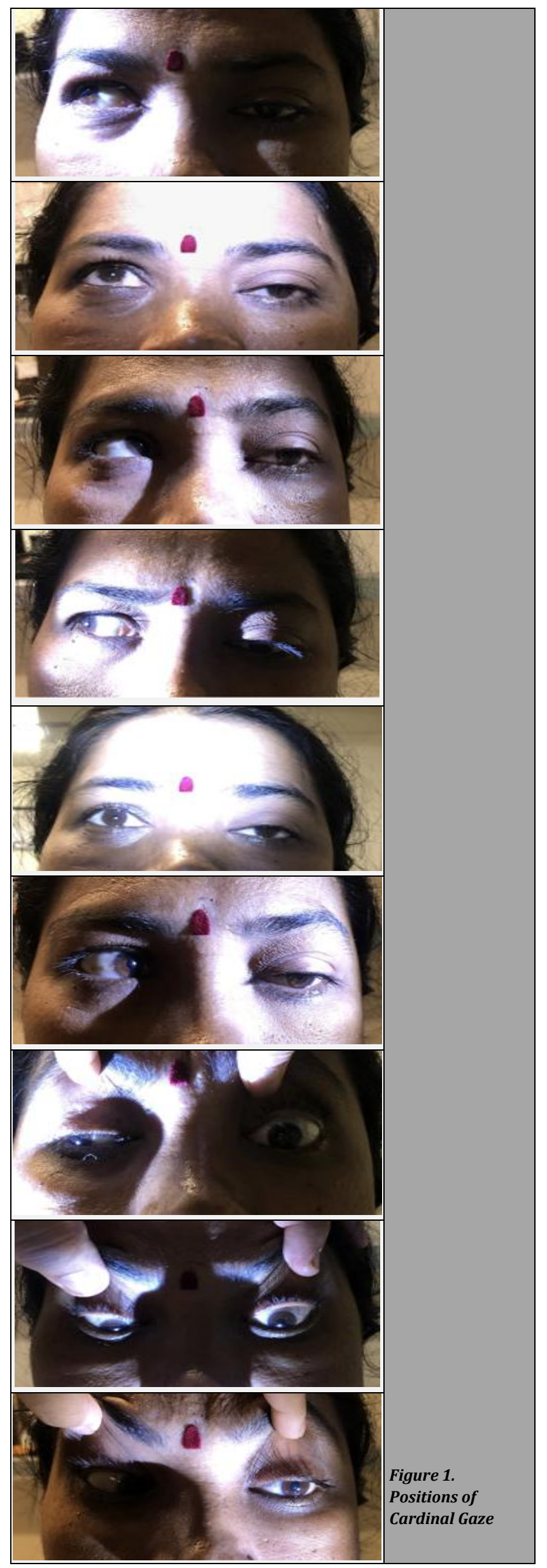

Radiological Investigations
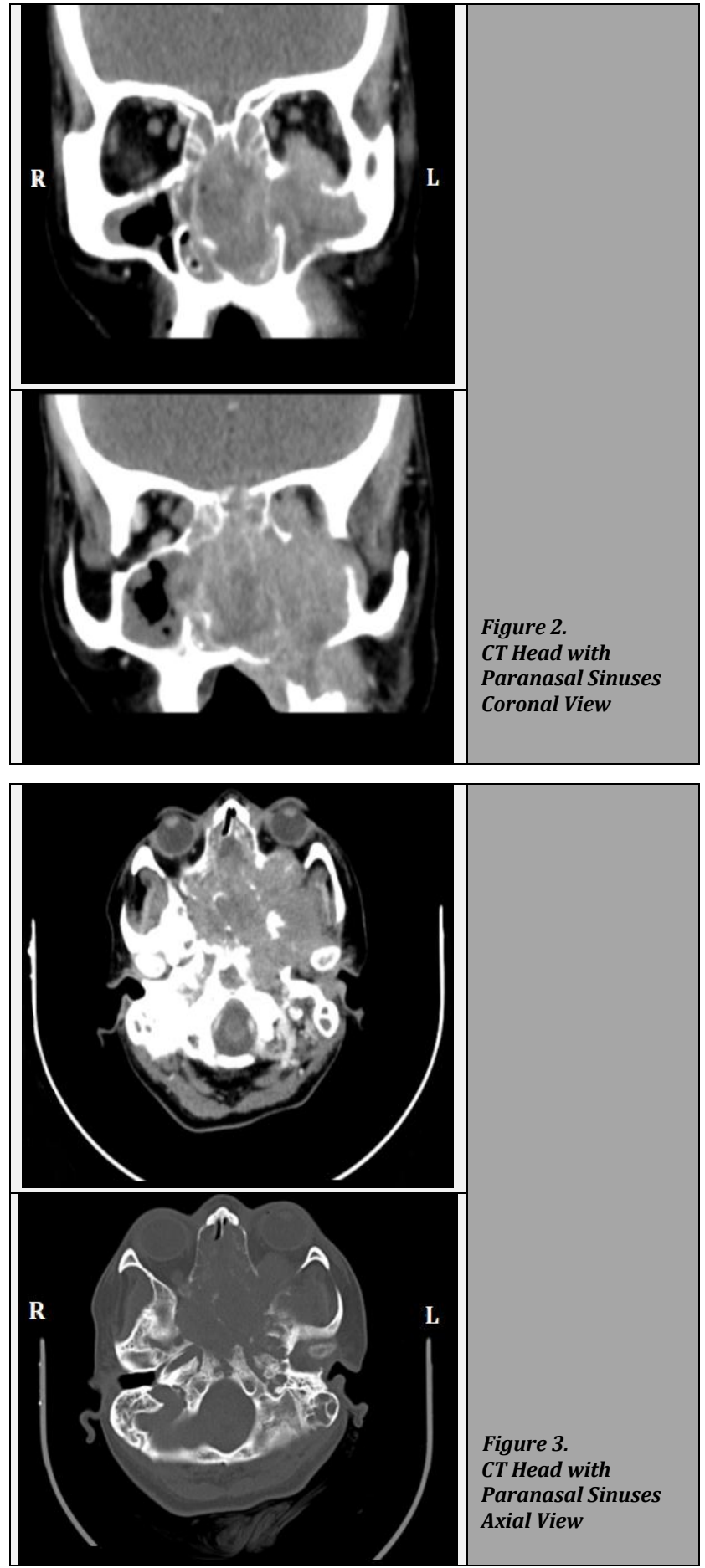

Figure 3.

CT Head with

Paranasal Sinuses

Axial View

\section{HISTOPATHOLOGY}

A biopsy was taken from nasal mass and sent to histopathological examination, which revealed-features suggestive of transitional cell or nonkeratinizing carcinoma. FNAC from submandibular lymph node reveals "deposits of nasopharyngeal carcinoma - undifferentiated type". Nasopharyngeal carcinoma was graded as IVA according to American Joint Committee on Cancer (AJCC) cancer staging. ${ }^{5}$ 


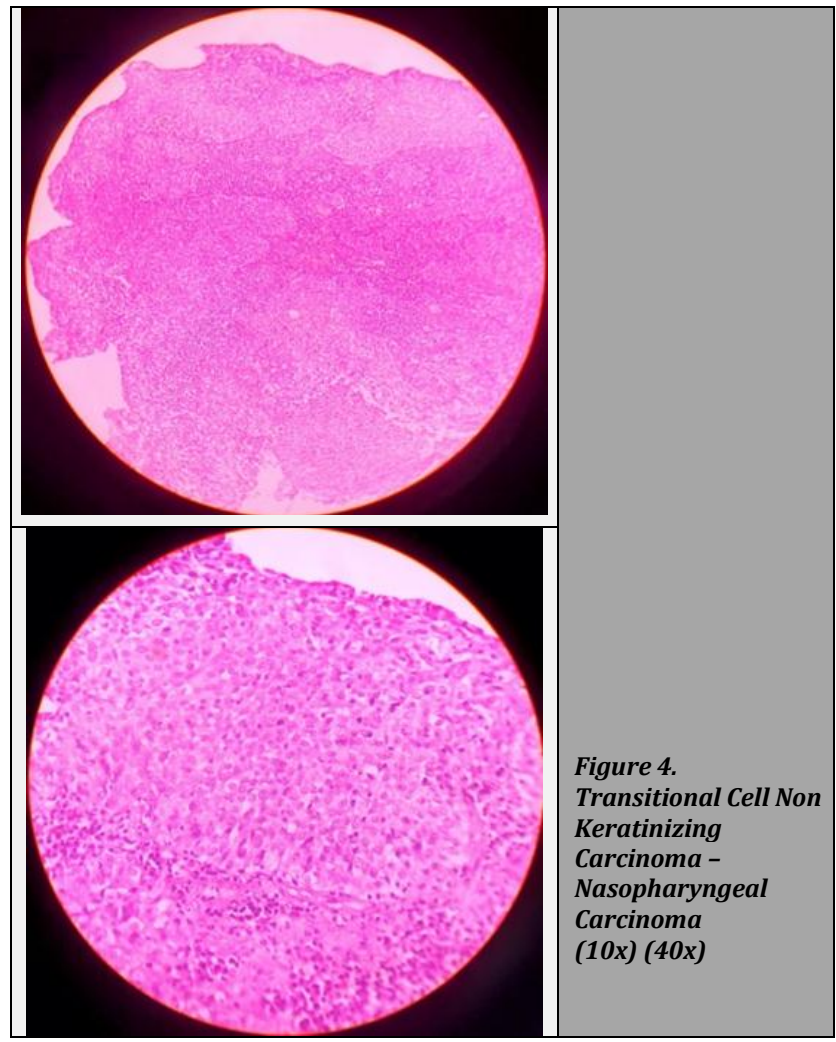

DISCUSSION OF MANAGEMENT

Plan of treatment was initial 3 cycles of chemotherapy followed by chemoradiation. Each cycle consisted of

- Injection ceftriaxone 1 gm intravenous (IV) 12 hourly

- Injection pantoprazole $40 \mathrm{mg}$ intravenous 12 hourly

- Injection dexamethasone $8 \mathrm{mg}$ intravenous stat

- Injection paracetamol $100 \mathrm{~mL}$ (10 mg / mL) IV $8^{\text {th }}$ hourly

- Injection docetaxel $88.2 \mathrm{mg}$ intravenous in $500 \mathrm{~mL}$ normal saline over $3-4 \mathrm{hrs}$.

- Injection cisplatin $88.2 \mathrm{mg}$ intravenous in $500 \mathrm{~mL}$ normal saline (NS) over 3 - 4 hrs.

- Injection 5-fluorouracil $884 \mathrm{mg}$ intravenous in $500 \mathrm{~mL}$ (NS) continuous intravenous infusion for $24 \mathrm{hrs}$. $\mathrm{x} 4$ days.

\section{DISCUSSION}

The case highlights an unusual symptomatic presentation of nasopharyngeal carcinoma with primary ocular manifestations along with nasal symptoms.

Paralysis or weakness of one or more muscle controlling ocular movements is called ophthalmoplegia. 6 Total ophthalmoplegia means weakness or paralysis of all muscles in the eye causing ptosis, restricted ocular movements in all directions of gaze, dilated non reacting pupil and loss of accomadation. ${ }^{6}$ It may be myogenic (involving muscles) or neurogenic (involving nerves innervating muscles). ${ }^{7}$

Nasopharyngeal carcinoma is a rare malignant tumour arising from nasopharyngeal epithelium. It is more common in China and south East Asia, but uncommon in India constituting only $0.41 \%$ of all cancers.
The risk factors include genetic susceptibility, EpsteinBarr virus infection, ${ }^{8}$ consumption of nitrosamines in salted fish, air pollution, smoke from burning incense stick and wood. It more commonly affects individuals in their 50 s to $70 \mathrm{~s}$, but not uncommon in 30 s. $^{2}$

Most common presentation in nasopharyngeal carcinoma in order of frequency would be cervical lymphadenoma, hearing loss, nasal obstruction, epistaxis, rhinolalia, otitis media and ocular symptoms occur at a later stage with advanced spread of tumour into orbit. ${ }^{2}$ Most common route of orbital extension is through pterygopalatine fossa and inferior orbital fissure. ${ }^{9}$ Further tumour extending through superior orbital fissure involves $5^{\text {th }}$ cranial nerve that can cause loss of corneal sensations.

But our case shows early tumour extension into orbit because of which patient presented with symptoms of ptosis and diminution of vision more prominently than associated nasal symptoms. Similar case was encountered by Das $\mathrm{S}^{10}$ where in patient had corneal vascularization and proptosis. CT scan showed a similar picture. Patient was treated with chemotherapy and orbital exenteration.

Routine treatment plan for nasopharyngeal carcinoma mainly depends on its staging. For stage I and II radiotherapy alone is sufficient. But for II and IV radiotherapy with adjuvant chemotherapy is required.

Another case studied by Kamath $\mathrm{GM}^{3}$ et al. also had similar complaints but vision was preserved and following chemotherapy ocular movements had returned to normal and ptosis had reduced significantly. Such results have yet to be studied in our report after complete treatment with chemotherapy. In our study patient has received one cycle of chemotherapy and ocular movements have improved a bit but ophthalmoplegia is not fully resolved.

Chemotherapy followed by radiotherapy has produced better outcomes in paediatric age group. ${ }^{11}$

Our patient will be followed up for resolution of ophthalmoplegia and ptosis during further chemotherapy sessions and later on following radio-chemotherapy.

Such cases, where in nasopharyngeal carcinoma presenting primarily with ophthalmic complaints though rare have to be thoroughly investigated and examiner should be very vigilant to rule out even the rarest of causes so that there can be early detection and timely treatment of such malignant tumours.

\section{CONCLUSIONS}

In such cases, where nasopharyngeal carcinoma presents primarily with ophthalmic complaints though rare have to be thoroughly investigated and examiner should be very vigilant to rule out even the rarest of causes so that there can be early detection and timely treatment of such malignant tumours. Though in our case, patient presented with ophthalmic symptoms, the primary site of lesion was in nasopharynx.

Financial or other competing interests: None.

Disclosure forms provided by the authors are available with the full text of this article at jemds.com. 


\section{REFERENCES}

[1] Hsu WM, Wang AG. Nasopharyngeal carcinoma with orbital invasion. Eye (Lond) 2004;18(8):833-8.

[2] Dhingra PL, Dhingra S, eds. Tumours of Nasopharynx. In: Diseases of ear, nose and throat \& head and neck surgery. $7^{\text {th }}$ edn. Reed Elseivier India Private Limited 2014:265-8.

[3] Kamath GM, Nayak MK, Gupta M, et al. Resolution of total ophthalmoplegia following treatment in a case of nasopharyngeal carcinoma: a case report. Journal of Clinical Ophthalmology and Research 2015;3(3):148-50.

[4] Lenzi GL, Fieschi C. Superior orbital fissure syndrome. Review of 130 cases. Eur Neurol 1977;16(1-6):23-30.

[5] American Joint Committee on Cancer (AJCC). AJCC cancer staging manual. $8^{\text {th }}$ edn. New York: Springer 2017.

[6] Wai Man CYY, Smith T, Chennery PF, et al. Assessment of visual function in chronic progressive external ophthalmoplegia. Eye (Lond) 2006;20(5):564-8.
[7] Duke-Elder S. 1971 Neuro-ophthalmology, in system of ophthalmology. Part II. Vol. 12. London: Henry \& Kimptom 1972: p. 780

[8] Sang Woo JK, van Hasselt CA. Nasopharyngeal carcinoma. In: Gleeson M, ed. Scott-Brown's otorhinolaryngology, head and neck surgery. Vol. 2. $7^{\text {th }}$ edn. London: Edward Arnold Ltd 2008:2446-7.

[9] Luo CB, Teng MM, Chen SS, et al. Orbital invasion in nasopharyngeal carcinoma: evaluation with computed tomography and magnetic resonance imaging. Zhonghua Yi Xue Za Zhi (Taipei) 1998;61(7):382-8.

[10] Das S. Total ophthalmoplegia - a series of case reports. Delhi Journal of Ophthalmology 2020;30:67-71.

[11] Sahraoui S, Acharki A, Benider A, et al. Nasopharyngeal carcinoma in children under 15 years of age: a retrospective review of 65 patients. Ann Oncol 1999;10(12):1499-502. 